
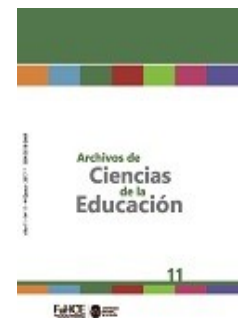

Fax

Archivos de Ciencias de la Educación, Vol 11, n 11, 2017, e021. ISSN 2346-8866

Universidad Nacional de La Plata.

Facultad de Humanidades y Ciencias de la Educación.

Departamento de Ciencias de la Educación.

\title{
La Didáctica y su compromiso con la práctica. Una reflexión sobre los saberes docentes
}

Didactics and its commitment to practice. A reflection from the teaching knowledge

\section{Ana Lía Cometta}

Universidad Nacional de San Luis, Argentina | acometa@unsl.edu.ar

\section{PALABRAS CLAVE}

Relación conocimiento/acción

Práctica docente

Saberes docentes

Carácter propositivo de la didáctica

\section{KEYWORDS}

Knowledge/action relationship

Teaching practice

Teacher knowledge

Proposed dimension of the didactics

\section{RESUMEN}

Este artículo retoma el carácter propositivo de la Didáctica como uno de los temas/problemas que enfrenta la Didáctica General en la actualidad. La contribución responde a la intención de reconfirmar el compromiso de la disciplina con las prácticas docentes y de enseñanza en un momento de desconfianza hacia la escuela, los docentes y las instituciones que los forman. El abordaje del tema impone considerar una actualización de los debates acerca de la relación entre conocimiento y acción, colocando a los saberes o conocimientos docentes como un constructo potencialmente articulador. Finalmente, se proponen algunas notas o rasgos orientadores que debiera presentar la producción didáctica para contribuir con las acciones de los docentes en los contextos de sus prácticas cotidianas.

\section{ABSTRACT}

The present research work resumes the propositional character of Didactics as one of the topics of concern that are being dealt with by General Didactics nowadays. Our aim is to reaffirm Didactics commitment to teaching and learning practices in a time when distrust of teacher training professionals, schools and institutions is common. This topic implies an up-to-date debate about the relationship between knowledge and action, placing teaching knowledge as a potentially articulating construct. We include some guiding features of didactic production that could help teachers' actions in their day-to-day practices.

Cita sugerida: Cometta, Ana L. (2017). La Didáctica y su compromiso con la práctica. Una reflexión sobre los saberes docentes. Archivos de Ciencias de la Educación, (11), e021. https://doi.org/10.24215/23468866e021 


\section{Presentación}

“Si la enseñanza no se concibe como una tarea de pura inspiración, es obvio que debe ser planificada de alguna manera, que se debe disponer (por parte del docente) de recursos para llevar adelante lo planificado, y de otros, por si los previstos no resultan en la emergencia de su puesta en práctica. (...) Y alguien, en términos de disciplinas, no de personas, debe ocuparse de todo ello. Para algunos y que se disculpe la humorada es el caballero inexistente...que resultó ser una dama (parafraseando a Italo Calvino), porque el menester resulta poco académico y excesivamente doméstico. Pero el menester en cuestión no es irrelevante para quien enfrenta la práctica cotidiana en el aula. Y aquí radica, tal vez, el quid de la cuestión. Entre las urgencias de lo cotidiano y las lógicas demoras de la construcción teórica, está ese actor social que es el docente”

(Barco, 1989, p. 19).

El texto de Susana Barco constituyó una suerte de reencuentro, académico y afectivo que me posibilitó recuperar algunas cuestiones e ideas potentes inherentes a la Didáctica que, a casi 30 años, mantienen la vigencia de las preocupaciones sustantivas de la disciplina: la justificación de la dimensión técnica (devenida en tecnológica con la ingeniería didáctica), la demanda de algún tipo de intervención en la práctica, la opacidad de su objeto y hasta la debilidad de su propia existencia. Se sabe que existe pero es poco visible por los docentes en las urgencias mundanas y cotidianas de sus prácticas. Estas preocupaciones admiten ser escrutadas hoy desde una producción pedagógica y didáctica, amplia y diversa, que plantea nuevos interrogantes y problemas al mismo tiempo que resignifica lo que Litwin (1996) denominó la “agenda clásica”. 1

Entre 1980 y 1990, comienza a debilitarse la racionalidad técnica que actuó como marco de referencia de la educación, la formación y socialización de los docentes durante gran parte del siglo XX, en Argentina y en otros países latinoamericanos y en países de la Europa Continental. Así comienzan a adquirir solidez y difundirse nuevos enfoques y perspectivas como parte de un movimiento denominado genéricamente “de reconceptualización” del cual Barco, como parte de un grupo de didactas, es una figura representativa. $\underline{2}$

La “reconceptualización didáctica”, a la que se refiriera inicialmente Pérez Gómez (1987), ${ }^{3}$ se trata de "un movimiento amplio, de variadas raíces teóricas que estructura su posición como respuesta al tecnicismo. Se apoya en un modo alternativo de entender la práctica y en nuevas descripciones de la conducta del profesor" (Feldman, 1999, p. 48). En este movimiento se incluyen variados aportes de diverso cuño y procedencia que, sin embargo, comparten algunos supuestos comunes (Pérez Gómez, 1987):

- Considerar el mundo de los significados, es decir, el flujo de acontecimientos y transacciones explícitas y tácitas que acontecen en la complejidad de un aula.

- Conceder importancia a las variables mediacionales del profesor, el alumno y el contexto. La investigación de la enseñanza debe acudir a los modelos antropológicos que respeten el espacio natural y se centren en el análisis de casos, y al enfoque naturalista que puede 
romper el aislamiento endémico y el divorcio histórico entre la investigación y la intervención didáctica desde la que el profesor se implica en la perspectiva de la “investigación acción”.

- Resaltar la intervención del profesor como sustantiva. De allí que la investigación didáctica tiene que identificar y explicar la perspectiva pedagógica y la plataforma teórica (explícita o tácita) desde la que los docentes interpretan la enseñanza para establecer reglas de acción que resuelvan los problemas de su intervención.

Desde este movimiento reconceptualizador -y a partir de las nuevas contribuciones y discusiones que se plantean en el campo didáctico en un momento de desconfianza hacia la escuela, los docentes y las instituciones que los forman- quiero reactualizar la cuestión del carácter propositivo/normativo de la Didáctica y su relación con la enseñanza y el sujeto docente; asunto que, se recorta como uno de los temas/problemas que enfrenta la Didáctica General en la actualidad.

Reafirmando el compromiso de la disciplina con las prácticas de enseñanza y su mejoramiento, el abordaje del tema impone una actualización de los debates acerca de la relación Teoría-Práctica o conocimiento y acción, situando al docente y sus saberes como un constructo articulador.

\section{El carácter propositivo/normativo de la Didáctica: entre la teoría y la práctica}

Para reconocer las “marcas” de la Didáctica como disciplina teórica y campo de prácticas, es necesario entender su constitución en relación con la historia de la escolarización y la conformación de la profesión docente o el oficio de enseñar.

En consonancia con una concepción utópica de la educación y la sociedad, desde sus primeros postulados teóricos la disciplina se proyectó “como una normatividad altamente estructurada, con sólidas prescripciones acerca del 'saber hacer' del maestro para lograr el 'deber ser' del modelo pedagógico propuesto” (Barco, 1989, p. 8). Esta visión normativa de la Didáctica funcionó, a la manera de bisagra, entre la utopía de la educación y las prácticas educativas; integrando, durante tres siglos, “explicación, norma y utopía” (Davini, 1996). A partir de los años ’70, la normatividad de la Didáctica se diluyó, empobreció o perdió vigencia, porque la especificación de reglas para la acción cedió paso a la comprensión o a la crítica. La teoría didáctica se alejó de los docentes y su práctica. Esta distancia puede interpretarse de diversas maneras:

- Ante el abandono de los supuestos referidos al método universal y la enseñanza eficaz, la disciplina quedó sumida en "megateorías" construidas desde un discurso interpretativo con aportes provenientes de la sociología del currículum (Davini, 1996) que, si bien diversifican y nutren ampliamente el pensamiento pedagógico y didáctico con nuevas categorías, $\stackrel{4}{-}$ no fueron suficientemente comprendidos (Salinas, 1995) o resultaron retóricos por su ajenidad respecto de la cultura pedagógica de los docentes y la tradición didáctica (Bolívar, 2003). A esta dilución también parecen haber contribuido los estudios provenientes de la etnografía, el interaccionismo simbólico o la ecología que, inicialmente alejados de la perspectiva didáctica, mostraron otra visión de la escuela y las aulas. El abordaje de temas didácticos por 
fuera o en los bordes de la disciplina unido a la pérdida de la visión común de su objeto parecen haber contribuido a debilitar el carácter propositivo/normativo de la Didáctica (Salinas, 1995). $\underline{5}$

- A raíz del imperio de la racionalidad tecnocrática se produjo una desvinculación entre las prácticas cotidianas en el aula y la reflexión teórica, colocando a la Didáctica en una posición de precariedad y fragilidad epistémica (Edelstein, 2007), como territorio de anclaje de acciones especializadas debilitadas.

- A partir del abandono de la impronta propositiva/normativa de la Didáctica (General), las propuestas de acción fueron “colonizadas” por los especialistas en las didácticas especiales desde teorías fragmentarias (Davini, 1996).

- Tal como se plantea, la problemática del debilitamiento del carácter propositivo/normativo de la Didáctica, y en consecuencia, la distancia entre el discurso didáctico y la acción, remiten al "valor de uso” $\underline{\mathbf{6}}$ del conocimiento didáctico para los practicantes en tanto disciplina comprometida con la práctica y su mejora (Camilloni, 1998), porque la normatividad asocia teoría y acción. $\underline{7}$ Si se concede al conocimiento didáctico un valor de uso para los docentes, la Didáctica debiera proveer de criterios básicos de acción que orienten las prácticas de enseñanza, posibilitando elegir entre diversas alternativas, adecuándolas al contexto y los sujetos, con la finalidad de transformar las prácticas en los ámbitos educativos (Picco, 2014). Esto es porque la Didáctica es un conocimiento que opera en términos situados y situacionales, de manera que requiere menos de modelos formales y más de principios de procedimiento. Según Feldman, “...los principios no pueden simplemente aplicarse, sino que necesitan ser interpretados por quienes están involucrados en la situación. Cuando son aplicados con independencia del caso en cuestión se convierten en reglas” (1999, p. 130). Asumiendo una relación de complementariedad de la teoría con la acción pedagógica, no se puede eludir la inclusión del sujeto docente en su doble papel de destinatario (del discurso didáctico) y protagonista (de la acción pedagógica). A continuación, remarcaremos algunos rasgos de esta relación, que resultan de interés en el campo pedagógico y didáctico (Cometta, 2001b).

En el ámbito educativo, una creencia tan habitual como poderosa -que responde a un pensamiento dicotómico- es aquella que identifica la práctica como lo urgente, lo particular, lo que hacen los docentes en su trabajo cotidiano; y la teoría, como lo universal e intemporal, lo que elaboran los investigadores a través de un proceso de indagación (Carr y Kemmis, 1988, pp. 20-21). Al entender teoría y práctica como dos esferas excluyentes, en oposición, se destaca la diferencia entre pensamiento y acción, de manera que "al aceptar el doble supuesto de que toda actividad práctica es a-teórica y que toda teoría es no práctica, este enfoque subestima la medida en que quienes desarrollan prácticas educativas tienen que reflexionar sobre lo que tratan de hacer, y por lo tanto, teorizar sobre ello" (Carr, 1996, p. 89). Según el autor, la superación de este pensamiento dicotómico es posible a partir de la praxis que, como forma de acción reflexiva, puede transformar la teoría que la rige. La utilidad de la teoría no es proporcionar reglas de actuación, como en la modalidad técnica, sino mejorar la base de conocimiento que informa las decisiones en situaciones 
prácticas a través de la sabiduría práctica, como disposición moral e intelectual (Carr, 1990). Para Carr (1996) la práctica puede regirse por una teoría bajo la forma de una idea de sentido común tácita, implícita y no articulada a la manera de marco conceptual subyacente; o bien, por la teoría elaborada que se presenta en forma de principios generales o leyes. Desde otra perspectiva, Schwab (1974) rechaza la confianza en la teoría como un saber seguro para dirigir y controlar la práctica, aunque le asigna dos utilidades: la de informar, liberando a los involucrados de producir la información necesaria y la de iluminar los problemas que se presentan en la práctica (Basabe, 2007, p. 209).

Desde una "nueva epistemología de la práctica” y en referencia a la formación de profesionales, Schön (1998) propone la articulación de la teoría y la práctica a través de la reflexión en la acción: "Cuando alguien reflexiona desde la acción se convierte en un investigador en el contexto práctico. No es dependiente de las categorías de la teoría y de la técnica establecidas, sino que construye una nueva teoría de un caso único” (1998, p.72).

En la perspectiva didáctica, los aportes de Feldman (1999) y Camilloni (1998) señalan la relación indirecta o mediatizadora entre la teoría didáctica y la acción, puesto que el valor de la teoría dependerá del uso que los practicantes puedan hacer de ella. A ellos les cabe reconstruir su significación teórico-práctica de modo que les permita iluminar la situación particular y la interpretación que de ella se hace, fruto de la reflexión crítica y la decisión creativa.

Algunas consideraciones para la Didáctica, la normatividad y su relación con la práctica:

- Las situaciones de la práctica implican la toma de decisiones y deliberaciones éticas, vinculadas a las consecuencias de la acción, a través la razón y la reflexión.

- La teoría y la práctica están expuestas al cambio y se transforman mutuamente a través de la acción reflexiva y crítica.

- Las teorías abarcan creencias, esquemas de pensamiento, saberes implícitos, como así también marcos proposicionales producto de la investigación; por lo que la práctica puede estar orientada por teorías más o menos coherentes y de diverso alcance.

- La utilidad de la teoría (didáctica) para la práctica (enseñanza) depende del sentido pedagógico y valor social que le otorga el docente (Camilloni, 2007).

\section{Saberes, docentes y profesionalidad}

A partir del movimiento de la nueva epistemología de la práctica (Schön, 1992; Tardif, 2004; Zeichner, 2010), saber, docente y profesionalidad aparecen como conceptos inseparables. Esto se debe al creciente desarrollo de investigaciones orientadas a la enseñanza y a los profesores que reflejan las tendencias de las reformas educativas actuales en el plano internacional (de Matos, 2007). .9 Paulatinamente, el constructo saber(es) docente(s) (o "saberes de oficio" o "saberes profesionales”) empieza a imponerse; respondiendo a las nuevas maneras de entender las relaciones entre la teoría y la acción pedagógica. Así, los “saberes docentes” presuponen que la práctica docente y la enseñanza son prácticas cotidianas que acontecen en escenarios escolares, como 
lugares de trabajo de los docentes. Los docentes, como sujetos reflexivos, racionales y creativos, sustentan esas prácticas (según decisiones, intervenciones que realizan) en saberes que han sido producidos y/o apropiados en sus trayectorias escolares y profesionales de diversas maneras.

La cuestión de los saberes retoma, en cierta manera, aquello que Terhart (1987) denominó “formas de saber” para referirse a la relación entre el saber pedagógico y la acción educativa desde el ángulo del profesor. Estas formas de saber refieren tanto a los contenidos que un profesor debe dominar como así también a diferentes clases de capacidades -verbalizables y no verbalizables- y actitudes que se amalgaman configurando la tan mentada "gramática parda” de la docencia.

Dentro de la amplitud de aportes del campo pedagógico interesa destacar dos improntas iniciales al concepto de “saber” (Porta y Cometta, 2017). Una, proveniente del campo de la formación de adultos fue desarrollada en Francia por Ferry y Beillerot a fines de la década del '70. Para estos autores "la noción de saber va a designar un conjunto de cosas afirmadas en una realidad social y profesional. No es por casualidad entonces que los prácticos se encuentren alrededor de esta noción (...). Saber es aquello que para un sujeto es adquirido, construido y elaborado por el estudio o la experiencia y se actualiza en situaciones y prácticas” (Beillerot, 1996, p. 89). La otra impronta ha sido desarrollada por Rockwell y Mercado a partir de las influencias del concepto de saber cotidiano de Heller y el enfoque etnográfico de investigación. Tal como lo expresan: "La resolución cotidiana de qué enseñar y cómo hacerlo supone no sólo la reproducción, sino la integración y generación de conocimiento por parte de quienes ejercen ese trabajo. Se trata de un conocimiento no formulado, no sistematizado, ni explicitado como tal, pero no por ello ausente” (Rockwell y Mercado, 1988, p. 70).

Recientemente, el análisis de las relaciones de los docentes con el saber didáctico o la "didáctica erudita” (Camilloni, 2007, p. 50) han puesto especial atención en los saberes, conocimientos que maestros y profesores usan en sus prácticas cotidianas (Edelstein, 2007).

Esta problemática se recorta como un tema de la Didáctica General por la potencialidad que encierra en el afán de recuperar los aspectos propositivos de la racionalidad que sustenta la acción en las aulas. Se vincula con la necesidad de mejorar la formación de los docentes y su profesionalidad, por lo que "un desafío crucial consiste en definir las vías que permitan explicitar el conocimiento de los docentes y convertirlo en experiencias susceptibles de análisis personal y comunicable a otros” (Edelstein, 2007, p. 45).

En el mismo sentido, en una de sus últimas obras, Díaz Barriga (2007) instala el debate de "pensar la Didáctica” con un interés por recuperar el sentido social, profesional y ético de la docencia.

Referir a los saberes docentes implica considerar la enseñanza como la acción pedagógica que se despliega en la vida cotidiana del aula y situarla en el contexto más amplio de la profesión y las instituciones, porque la enseñanza "es la acción de un docente, a la vez sujeto biográfico y actor social. Es acción situada, porque transcurre en un contexto histórico, social, cultural, institucional” (Basabe y Cols, 2007, p. 151). Como práctica social, la práctica docente (y la enseñanza) se presenta como una actividad altamente compleja, multidimensional, que demanda una implicación personal según las decisiones éticas y políticas que debe tomar y las intencionalidades pedagógicas que persigue. 
La cuestión del saber docente ha fluctuado entre dos polos, como “conocimiento objetivo” y “saber subjetivo” o personal; y entre dos peligros, “el mentalismo” y “el sociologismo”; que han signado la investigación en el campo de la Didáctica y la formación docente (Tardif, 2014). $\underline{10}$

Ahora bien, si la teoría didáctica no es suficiente para guiar la práctica, si el conocimiento es relativo y las respuestas técnicas no bastan para resolver los problemas asociados a ésta, cabría preguntarse: ¿Qué saberes ponen en juego los docentes en situaciones de acción profesional concreta? ¿Cómo intervienen respecto a las decisiones que toman? ¿Qué lugar ocupan los docentes en la producción de saberes en el ámbito de su profesión? ¿De qué manera lo hacen? ¿El saber pedagógico y didáctico elaborado por los especialistas, investigadores, didactas, constituyen todo el saber de los profesores? $\stackrel{11}{\text { Las }}$ respuestas a algunas de estas preguntas que marcan actualmente la investigación internacional sobre el tema, comparten algunos supuestos: existe un repertorio o base de conocimientos particulares a la función del profesor que lo diferencia de otros profesionales; lo que los profesores piensan y saben es relevante para comprender las decisiones y acciones que toman; los saberes docentes son plurales y heterogéneos, provienen de diversas fuentes y se adquieren en el tiempo en un proceso en el que convergen factores biográficos, institucionales, sociales, culturales, laborales, etc. (Tardif, 2004; Gauthier y otros, 1998).

\section{Visiones acerca del saber docente: racionalidad y normatividad}

Respecto a los saberes docentes, se abrió un nuevo campo de indagación parcialmente estructurado que enfrenta dos grupos de problemas. Uno referido a la variedad de corrientes y concepciones sobre saber y enseñanza, y el otro, desde el que se reconoce que se sabe muy poco acerca de la construcción de los saberes por parte de los docentes. $\frac{12}{}$ En razón de esto, se advierten dos excesos en la investigación sobre los saberes docentes: por un lado, considerar al docente como un actor dotado de una racionalidad basada exclusivamente en su cognición (sujeto epistémico); y por el otro, considerar toda la producción, discursos y prácticas como saber (propio del exceso de la etnografía que lleva a que el concepto pierda poder discriminatorio).

A continuación, y tomando como referencia los tipos de racionalidad que diferencia Tardif (2014) según el lugar (topos) del saber, se mencionan algunos aportes investigativos relevantes por la visión que otorgan al saber docente.

La visión representacional, mentalista y subjetivista del saber

Desde esta visión, se identifica a la subjetividad como el origen del saber. Se trata de todo tipo de certeza subjetiva producida por el pensamiento racional que puede asumir dos formas: como intuición intelectual que permite aprehender una verdad o como una forma de representación intelectual resultado del raciocinio. Saber alguna cosa es poseer una certeza subjetiva racional. Esta concepción del saber ligada a la subjetividad es el fundamento de la mayoría de las investigaciones de la psicología cognitiva.

En el terreno didáctico, el paradigma del "pensamiento del profesor”, orientado a clarificar la relación pensamiento-acción, tuvo un desarrollo considerable para "investigar los pensamientos y conocimientos de los/as profesores/as con la intención, tanto para comprender las concepciones, creencias, dilemas, teorías que gobiernan la práctica profesional, cuanto identificar los procesos que 
constituyen el aprender a enseñar y las categorías conceptuales en las que se articula el conocimiento básico para desarrollar la actividad profesional de la enseñanza” (Montero, 2002, p. 143).

En general, predomina una especie de “realismo” por el cual el docente ve la realidad según la representación individual y subjetiva que tiene de ella. En Europa, la consideración de la subjetividad y cognición de los docentes tuvo una inspiración de corte socio-constructivista. Desde esta perspectiva se interesan en los procesos de negociación, las representaciones mentales inter e intrasubjetivas y en otras dimensiones simbólicas de la enseñanza y que en Norteamérica se corresponden con la antropología cognitiva. Otros estudios, de amplio desarrollo en la actualidad, consideran la subjetividad del profesor desde la fenomenología existencial, (historias de vida, enfoques narrativos, relatos personales, etc.).

Desde la sociología crítica de inspiración neomarxista, la subjetividad de los docentes remite a categorías y lenguajes sociales que estructuran la experiencia de los actores en los procesos de comunicación e interacción cotidiana.

Más allá de las distintas perspectivas que ubican a la subjetividad (cognitiva, existencial o social) y a la cognición como lugar del saber, los aportes revelan la importancia de considerar al docente como un sujeto que piensa, siente, vivencia y tiene experiencias.

Otro aporte que también puede incluirse en la racionalidad subjetiva es el modelo de profesor intuitivo que indaga la relación entre los modos de conocimiento y el aprendizaje racional/intuitivo o explícito/tácito en el mundo laboral de los docentes. Para Atkinson y Claxton (2002), por ejemplo, la intuición constituye una dimensión de la reflexión y tiene importantes implicancias en la formación inicial de docentes.

\section{El juicio y la argumentación como lugares del saber}

Frente al discurso descriptivo que caracteriza a los estudios encuadrados en la visión anterior, los aportes que colocan a los juicios y argumentos como lugares del saber constituyen discursos normativos respecto a lo que sería deseable en la práctica.

Desde una visión que adjudica al juicio el lugar del saber, éste implica aquel discurso que afirma con razón alguna cosa y respecto de alguna cosa. A diferencia de la visión referida anteriormente, el saber es mucho más el resultado de un actividad intelectual (como el acto de juzgar) que de una intuición o una representación subjetiva. En términos de Habermas (1987, citado en Tardif, 2014) el juicio se refiere en este caso a una dimensión asertórica o proposicional. El saber reside en un tipo de discurso (una afirmación) que va más allá de la visión subjetiva aunque, en este caso, se limita al juicio de la realidad o empírico excluyendo los juicios de valor, las vivencias, etc.

En la visión que otorga a la argumentación un lugar central, el saber es definido como la actividad discursiva por medio de la cual el sujeto intenta validar una proposición o acción. Esta concepción traspasa el terreno de la subjetividad para alcanzar la intersubjetividad y también la relación de correspondencia con lo real para penetrar en una relación con el otro. El saber surge como una construcción colectiva producto de los intercambios entre los agentes. No se limita al conocimiento lógico o empírico sino que también se encuentra en el discurso normativo porque se puede argumentar sobre su validez según criterios que implican, siguiendo a Gadamer (1992), la idea de 
un pacto comunicacional dentro de una comunidad de discusión.

Desde la perspectiva argumentativa y social, Gauthier y otros (1998) $\underline{13}$ consideran que el saber de los docentes es expresión de una razón práctica que depende mucho más de la argumentación y los juicios que de la cognición y la información. La exigencia de racionalidad está marcada por su inclusión en el interior de una situación y de una cultura compartida de las cuales el sujeto posee apenas un conocimiento siempre parcial, contextualizado, situado en el tiempo y el espacio. Por lo cual, los saberes en los que se apoyan los profesores dependen de las condiciones sociales e históricas en las que ejercen su profesión.

Lo que guía la acción de los docentes es la razón práctica. El profesor toma decisiones que no son arbitrarias, ilegales, inmorales o inoportunas porque siempre refiere a los fines, a las reglas de acción, de manera que las decisiones tienen que encuadrarse en un contexto de valores y de normas en relación a los cuales pueden ser criticadas y justificadas.

Un aporte desde las perspectivas expuestas refiere al uso de la investigación en la práctica y la manera de involucrarse en la praxis reflexiva desde el razonamiento y el debate práctico, como los exámenes post-hoc de las acciones o las exposiciones de la acción para explicar o justificar lo que los enseñantes hacen (Fenstermacher y Richardson, 1998). Desde esta posición se admite que, en sentido normativo, los argumentos prácticos ofrecen instancias mejores o peores para que un agente mejore su razonamiento práctico, ya sea porque el docente aporta razones mejor fundamentadas o más valiosas. A partir de estas ideas, Bolívar (1995) considera que la reconstrucción es el proceso de evaluar el argumento práctico elicitado juzgando su adecuación según sus fundamentos morales, empíricos, lógicos, etc.; y por medio de esta revisión lograr una base más profunda para la acción. La reconstrucción resulta normativa porque conduce a un mejor o peor razonamiento práctico, lo que es o no es una buena enseñanza (Cometta, 2002).

\section{La visión de confianza en el saber de experiencia, personal y práctico o de la episteme cotidiana}

La racionalidad respecto del saber también se vincula a aquellos conocimientos que sirven de base a los argumentos que los sujetos ofrecen respecto a lo que piensan y hacen. Los saberes comunes e implícitos constituyen el episteme cotidiano. En la vida diaria, los discursos y los actos se apoyan en saberes que otorgan un marco de inteligibilidad y dan sentido a las cosas que aprehendemos. Allí la exigencia responde más bien a la racionalidad del saber social como lo común compartido por una comunidad de actores; saber práctico que obedece a varias lógicas de comunicación y está enraizado en razones, motivos e interpretaciones que implican variedad de juicios (Tardif, 2014, pp. 200-202).

Esta visión es probablemente la que ha merecido más atención en investigaciones de corte interpretativo sobre saberes docentes, destacándose los aportes de Carter, Elbaz, Clandinin y

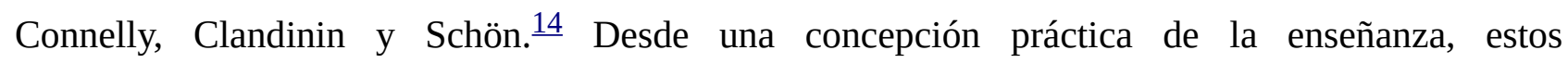
investigadores consideran que la interpretación de las situaciones supone, necesariamente, una estructura personal, tácita y subjetiva de comprensión. Conocer esta estructura implica introducirse en el mundo de las percepciones, emociones temporales e imágenes de los docentes en el sentido que lo expresa Carter: "el conocimiento práctico es aquel que los docentes tienen de las situaciones de clase y los dilemas con los que se enfrentan actuando propositivamente en dichos ámbitos; 
conocimiento que puede ser analizado a través de las comprensiones personales que los docentes poseen en circunstancias prácticas en las que trabajan” (Bolívar,1995, p. 24). En esta línea, en un estudio pionero, Elbaz (1983) indagó las orientaciones (situacional, personal, social, experiencial y teórica), los niveles de organización (reglas prácticas, principios e imágenes) y los contenidos del saber o conocimiento práctico (del yo mismo, del ambiente de enseñanza, de la materia, del currículo y de la instrucción).

Desde la investigación narrativa, Connely y Clandinin (1984, 1985. citado en Montero, 2002) también han aportado en esta perspectiva. Representan el aspecto más personalista de los estudios del conocimiento personal práctico, considerado fundamentalmente como un conocimiento experiencial y estructurado por imágenes. Para Clandinin la reflexión resulta un proceso esencial para la práctica porque, a través de ella, un individuo puede hacer consciente y analizar sus imágenes y, en consecuencia, su propia experiencia histórica.

Desde el campo de la formación profesional, los aportes de Schön (1992) van en el mismo sentido, puesto que el profesor es un profesional que posee un conocimiento propio a partir del cual analiza las situaciones, delibera y decide. El autor propone un nuevo modelo de formación profesional que denomina “profesional reflexivo”. Caracteriza la práctica profesional desplegada en tres niveles diferentes de conciencia o explicitación del pensamiento: conocimiento en acción, reflexión en la acción y reflexión sobre la acción. Como el conocimiento en la acción es tácito, puede describirse a través de la observación y la reflexión. Pero, si bien la reflexión -entendida como proceso cognitivo- permite llevar a conciencia algo de la acción que despierta nuestra atención, no implica que pueda ser verbalizada (...)“cuando el práctico responde a las zonas indeterminadas de la práctica manteniendo una conversación reflexiva con los materiales de tales situaciones, rehace una parte de su mundo práctico y con ello revela el proceso, habitualmente tácito, de construcción del mundo que subyace a su práctica” (Montero, 2002, pp. 171-172).

Lo que interesa destacar de estos aportes es que, desde el enfoque interpretativo, los saberes que ponen en juego los profesionales prácticos (docentes) cuando actúan son idiosincráticos, tácitos y personales, construidos a partir de la experiencia. Para ellos, la práctica reflexiva es un proceso privado (excepto en Schön que incluye la participación de “tutores”). Mientras que, desde otras perspectivas (Tardif, Gauthier), si bien este saber es implícito tiene un carácter social producto de la tradición y la cultura de la profesión docente.

Como parte de los saberes prácticos, resultan de interés los aportes referidos al saber didáctico de los contenidos. Desde esta posición, Shulman recupera una dimensión insoslayable del conocimiento profesional o el paradigma olvidado que es objeto actual del desarrollo de las didácticas específicas. Sobre el particular, expresa:

Educar es enseñar de una forma que incluya una revisión de por qué actúo como lo hago. Mientras el conocimiento tácito puede ser característico de algunas acciones de los profesores, nuestra obligación como formadores de profesores debe ser hacer explícito el conocimiento implícito (...) esto requiere combinar la reflexión sobre la experiencia práctica y la reflexión sobre la comprensión teórica de ella (Shulman, 1989, p. 65$). \underline{15}$ 
La categoría de conocimiento didáctico o saber pedagógico sobre el contenido, deja entrever un interés por el conocimiento práctico reflejado en su propuesta de conocimiento proposicional, de casos y estratégico. Se interesa por la transformación del conocimiento proposicional en conocimiento práctico. En un estudio reciente, Gudmundsdottir (1998) ${ }^{16}$ destaca las cualidades narrativas y pedagógicas del saber sobre los contenidos para una mejor compresión de la potencia heurística del concepto. En estas contribuciones, mientras Shulman considera al saber didáctico sobre el contenido como un conocimiento explícito y académico que constituye la base de la profesionalidad docente, para Gudmundsdottir se trata de un conocimiento tácito que forma parte del saber práctico del docente.

\section{La racionalidad implicada en el saber (docente)}

En razón de la carga semántica del término en el ámbito de la Ciencias Sociales, en este último apartado resulta pertinente retomar las características inherentes a la "exigencia de racionalidad” de los saberes docentes aludida anteriormente, Si bien desde un movimiento con eje en Gran Bretaña, se valoriza el componente racional del conocimiento y se encaran estudios que apuntan a proveer una base más científica a la enseñanza rescatando su componente teórico (Furlong, 2002); se coincide con otra posición desarrollada en Canadá por Tardif (2004, 2014) y Gauthier (1998), entre otros representantes.

Estos autores señalan que el saber de los docentes es un saber social porque: es compartido en una situación colectiva de trabajo; es producido socialmente como resultado de la negociación entre diversos grupos; sus propios objetos son prácticas sociales; la historia de las ideas y prácticas pedagógicas revela que el saber de los profesores responde, en términos de Bourdieu y Passeron (1977), a un arbitrario cultural; es adquirido y construido a lo largo de una trayectoria de vida y una carrera profesional.

Evitando los excesos del cognitivismo y la etnografía, Tardif expresa que llama saber:

...únicamente a los pensamientos, ideas, juicios, discursos, argumentos que responden a ciertas exigencias de racionalidad. Yo hablo por medio de razones, de declaraciones, de procedimientos, etc., por mi discurso o por mi acción ante otro actor que me cuestiona sobre la pertinencia o el valor de ellas. (...) estas razones son discutibles, criticables y revisables (2014, p. 199).

Para estos autores, la idea de racionalidad no es normativa; es flexible y diferente a la racionalidad de la investigación universitaria. Los criterios de racionalidad no pueden establecerse de antemano sino que son fruto de la discusión y las razones presentadas por los actores. La idea de exigencia de racionalidad está relacionada con un modelo intencional del actor humano según el cual las personas actúan en función de objetivos, proyectos, finalidades, medios, deliberaciones, etc. El docente, como sujeto racional, autónomo y creativo, participa en la producción del saber acerca de su práctica a través de juicios y argumentos que actúan, en parte, como discurso normativo sobre ésta. 


\section{Reflexiones finales}

En la perspectiva de lo expuesto y desde los nuevos significados acerca del carácter normativo/propositivo de la Didáctica, se comparte que la disciplina tiene una relación directa con la mejora de la práctica. Pero, si su intervención sobre ella es mediada por las comprensiones, reflexiones, juicios y argumentos prácticos de los practicantes, resulta por demás sugerente retomar la pregunta que formula Basabe: “¿De qué modo puede la didáctica orientar la producción y la intervención de manera que constituya una plataforma conceptual e instrumental útil para la deliberación, la decisión y la actuación de maestros y profesores en el contexto escolar?” (2007, p.227). Para acercar algunas respuestas provisorias al tema:

- Es necesario reconocer los límites de la teoría didáctica en la guía y orientación de la práctica educativa. La disciplina tiene que ocuparse del problema como aspecto constitutivo de su tarea, por lo que debiera incorporar como dimensión central de su producción la consideración de los contextos y los modos en que ese conocimiento es recuperado para su uso. Los saberes de los docentes también son limitados y su construcción y movilización obedecen más bien a una razón práctica que les resta relevancia en el marco del formalismo predominante aún en la investigación académica que bajo la pretensión de objetividad deja de lado la vivencia, lo inesperado, la propia perspectiva y la situacionalidad (Contreras y Pérez de Lara, 2010).

- Se requiere ampliar el horizonte normativo. En la acción y desde la racionalidad cotidiana, las creencias, ideologías, representaciones y concepciones otorgan al docente un marco para describir y explicar su actuación porque corresponden a saberes acumulados en la historia de la cultura y de la profesión. Esta normatividad es propia de lo que Camilloni (2007, pp. 4549) denomina didáctica ordinaria o de sentido común. La normatividad también puede construirse en distintos ámbitos (escolares, investigativos) cuando se favorece la formulación de juicios y argumentos prácticos desde los cuales los docentes justifiquen por qué hacen lo que hacen y cómo lo hacen. En este sentido, los juicios y argumentos se vuelven normativos cuando en un colectivo de docentes, o en una tarea conjunta y solidaria entre investigadores y docentes, son evaluados y valorados como buenas maneras de hacer las cosas desde un sentido epistemológico, moral y social. Por su valor intrínseco, una teoría didáctica también puede tener potencialmente alcances normativos dependiendo de la interpretación y uso que los docentes hagan de ella. En todos los casos, para que la Didáctica tenga valor de uso para la mejora de las prácticas debiera formular de manera más amplia y abierta su discurso normativo, haciéndolo más explícito (en cuanto a contenido, fundamentos, condiciones y consecuencias) de modo que facilite la toma de decisiones de los docentes, además del análisis y evaluación de tales propuestas. La normatividad didáctica debiera expresarse bajo la forma de principios de procedimiento más que como reglas de actuación que promuevan su uso en los contextos de prácticas (Basabe, 2007). En este sentido, las propuestas de modelos de enseñanza de Joyce y Weil (1985), los enfoques de enseñanza de Fenstermacher y Soltis (1999), los distintos puntos de vista de la enseñanza de Jackson (2002), las configuraciones didácticas (Litwin, 1997) y las buenas prácticas de los docentes de Bain (2007) constituyen una interesante producción didáctica sobre la 
cuestión.

- La profesionalización de la docencia requiere, en los próximos tiempos, avanzar en una autonomía contextualizada dando lugar a la consolidación de dispositivos de colaboración profesional entre docentes e investigadores (Edelstein, 2007, p. 48). Respecto de la producción del conocimiento didáctico es importante considerar que hay distintos saberes que responden a lógicas diferentes y un saber que los docentes construyen colectivamente en las prácticas a partir del análisis reflexivo y la argumentación que merece ser considerado al interior de la producción didáctica, en tanto se vuelve público y está sujeto a la crítica y la revisión. La investigación debiera avanzar en estudios colaborativos y de corte cualitativointerpretativo como estudios de casos, relatos de experiencias, estudios biográficos, entre otros.

Con esta contribución solo he pretendido ampliar el campo de lo posible... de lo que saben y hacen los docentes, de cómo formarlos y la manera de emprender con ellos la aventura colectiva de construir Didáctica...

\section{Notas}

1 Litwin (1996) caracteriza como la agenda clásica de la Didáctica a las respuestas vinculadas con cuestiones técnicas o instrumentales referidas a los objetivos, contenidos, currículum, actividades, evaluación y al aprendizaje; categorías que han sido revisadas a partir de los años '80 desde la perspectiva crítica.

2 Susana Barco es una pedagoga argentina especialista en temas curriculares y didácticos. Ya en 1975 publica uno de sus primeros artículos, “Antididáctica o Nueva didáctica”, en un número de la Revista de Ciencias de la Educación titulado “Crisis en la Didáctica” (2da. parte). Este número reúne, entre otros autores, a Iván Illich, Thelma Barreiro y Janine Filloux como expresión de los discursos críticos y contestatarios que empezaban a circular en el mundo académico y que Susana Barco y María Saleme se encargan de difundir en la Universidad y en los sindicatos de educadores. Con la apertura democrática reaparece la producción teórica del grupo reconstituido de intelectuales críticos del campo de las Ciencias de la Educación y la Didáctica (Barco, Saleme, Edelstein y Remedi) que revitaliza los estudios sobre Currículum (Mastroccola, 1999).

$\underline{3}$ Al referirse a este movimiento de reconceptualización, Pérez Gómez lo caracteriza como una fase pre-paradigmática de reajuste, creación teórica y metodológica en el campo de la Didáctica que incluye: asuntos vinculados al currículum, diseños de enseñanza más flexibles, adopción de enfoques mediacionales y ecológicos en la investigación, análisis de la comunicación en el aula como un sistema abierto, y cambios en las concepciones y métodos de evaluación. En el campo de la formación y perfeccionamiento del profesorado se abandona la idea del profesor como mero técnico orientándose al desarrollo de capacidades de procesamiento, diagnóstico, decisión racional, reformulación de proyectos, etc. (1987, pp. 200-202).

4 Acerca de los nuevos aportes que marcan el movimiento reconceptualizador en la Didáctica, la 
publicación pionera en idioma español de Gimeno Sacristán y Pérez Gómez (1985) publicada inicialmente en 1983, muestra un amplio panorama de temas y autores que eclosionan a principios de los '80 en Europa y Estados Unidos.

$\underline{5}$ Salinas (1995), en un esfuerzo que denomina “volver a pensar la Didáctica”, señala que a partir de los años '80, en España, el discurso didáctico ha operado un cambio vertiginoso por la aparición de temáticas novedosas desde diferentes discursos y perspectivas, referidas a la función docente, el profesor reflexivo, la recreación de la cultura, la diversidad, el desarrollo comunitario, el currículum, la formación del profesorado, los recursos tecnológicos, etc.

6 Salinas (1995) identifica dos categorías de valor práctico del conocimiento didáctico: el valor intrínseco y el valor instrumental. El primero deriva del conocimiento sistematizado sobre la realidad desde una determinada racionalidad que nos permite construir el mundo y comprenderlo. El valor instrumental puede ser identificado como el "valor de uso", derivado de ese conocimiento, que posibilite propuestas estratégicas de acción según las condiciones contextuales. Este valor de uso descansa en el pensamiento y en las acciones de profesores y profesoras en la realidad escolar. De allí los límites del discurso didáctico, por estratégico, parcial y contextual respecto al cambio escolar.

$\underline{7}$ En un trabajo anterior me he referido con más amplitud y profundidad a la cuestión de la base normativa y al carácter instrumental de la Didáctica (Cometta y otros, 2001a).

$\underline{8}$ Un desarrollo sobre los aportes de la investigación interpretativa y de la crítica ideológica en relación al conocimiento didáctico puede consultarse en Cometta, 2001b.

$\underline{9}$ Este texto, cuyo original está en portugués y los restantes que figuran en la bibliografía, han sido traducidos por la autora de este artículo respetando el sentido original dado por los autores.

10 La traducción corre por cuenta de la traductora de este artículo.

11 Tomado, en parte, de Tardif (2004, p. 26).

12 Un análisis más detallado de estos dos tipos de problemas se encuentra en Tardif (2014, pp.183185).

13 La traducción del original en portugués corre por cuenta de la autora de este artículo.

14 La referencia a estos autores se hacen desde el texto de Montero (2002). En el caso de los aportes de Schön se han consultado sus obras.

15 En: Bolívar (1995, p. 29)

16 En: Mc Ewan y Egan (1998).

\section{Bibliografía}

Atkinson, T. y Claxton, G. (2002). El profesor intuitivo. Barcelona: Octaedro.

Basabe, L. (2007). Acerca de los usos de la teoría didáctica. En Camilloni, A. (Comp.) El saber 
didáctico (pp. 201-231). Buenos Aires: Paidós.

Basabe, L. y Cols, E. (2007). La enseñanza. En Camilloni, A. (Comp.). El saber didáctico (pp. 125161). Buenos Aires: Paidós.

Barco de Surghi, S. (1989). Estado actual de la pedagogía y la didáctica. Revista Argentina de Educación. Asociación de Graduados en Ciencias de la Educación, Año VII, 12, 7-23.

Bain, K. (2007). Lo que hacen los mejores profesores de universidad. España: Universidad de Valencia.

Beillerot, J. (1996). La formación de formadores. Entre la teoría y la práctica. Buenos Aires: UBANovedades Educativas.

Bolívar, A. (1995). El conocimiento de la enseñanza. Epistemología de la investigación curricular. España: FORCE, Universidad de Granada.

Bolívar, A. (2003). Retos actuales del Área de Didáctica y Organización Escolar en el ámbito universitario: experiencias, interrogantes e incertidumbres. En Didáctica y Currículum. Reunión Área Didáctica y Organización Escolar. Valencia, España. Recuperado en: http://cmap.upb.edu.co/rid=1196125280484 1620456719 967/Bol\%C3\%ADvar\%20-Did \%C3\%A1ctica\%20y\%20curriculum.pdf

Bourdieu, P. y Passeron, J.C. (1977). La reproducción. Elementos para una teoría del sistema de enseñanza. Barcelona: Laia.

Camilloni, A. (1998). El sujeto del discurso didáctico. Praxis Educativa. Año III (3), 27-32

Camilloni, A. (2007). Los profesores y el saber didáctico. En Camilloni, A. (Comp.). El saber didáctico (pp. 201-231). Buenos Aires: Paidós.

Carr, W. (1990). Hacia una ciencia crítica de la Educación. Barcelona: Leartes.

Carr, W. (1996). Una teoría para la educación. Hacia una investigación educativa crítica. Madrid: Morata.

Carr, W. y Kemmis, S. (1988). Teoría Crítica de la Enseñanza. Barcelona: Martínez Roca.

Cometta, A. y otros (2001a). La Didáctica ¿tiene derecho a ser normativa e instrumental? Trabajo inédito. Facultad de Ciencias Humanas, UNSL.

Cometta, A. (2001b). La construcción del conocimiento didáctico desde la investigación y su relación con la práctica ¿Qué conocimiento? ¿Qué Didáctica? Fundamentos en Humanidades, Vol. 2 (003), 56-76

Cometta, A. (2002). La construcción del conocimiento profesional docente. Delineando puentes para una didáctica de la formación docente. En Bentolila, S. y Cometta, A. (Comp.). Educación y Enseñanza. Temas y cuestiones que atraviesan los procesos de formación docente (pp. 139-158). San Luis: Laboratorio de Alternativas Educativas.

Contreras, J. y Pérez de Lara, N. (Comps.) (2010). Investigar la experiencia educativa. Madrid: Morata. 
Davini, M. C. (1996). Conflictos en la evolución de la didáctica. La demarcación de la didáctica general y las didácticas especiales. En Camilloni, A. y otros: Corrientes Didácticas Contemporáneas (pp.41-73). Buenos Aires: Paidós.

de Matos, M. (2007). Curriculo, formação inicial do profesor e saber docente. Revista Vertentes (29). Recuperado de http://intranet.ufsj.edu.br/rep sysweb/File/vertentes/Vertentes 29/maria do carmo.pdf

Díaz Barriga, A. (2007). Pensar la didáctica. Buenos Aires: Amorrortu.

Edelstein, G. (2007). Didáctica y orientaciones prácticas. ¿Una obstinación o un desafío? Aportes al debate. Itinerarios Educativos (3), 38-59. doi: https://doi.org/10.14409/ie.v1i3.3913

Feldman, D. (1999). Ayudar a Enseñar. Buenos Aires: Aique.

Fenstermacher, G. y Richardson, E. (1998). La obtención y reconstrucción de debates prácticos en la enseñanza. Revista de Estudios del Currículum, Vol 1 (3).

Fernstermacher, G. y Soltis, J. (1999). Enfoques de la enseñanza. Buenos Aires: Amorrortu.

Furlong, J. (2002). La intuición y la crisis de la profesionalidad entre los docentes. En Atkinsons, T. y Claxton, G. El profesor intuitivo. Barcelona: Octaedro.

Gadamer, H. (1992). Verdad y método. Tomo II. Salamanca: Sígueme.

Gauthier, C. y otros (1998). Por uma teoría da pedagogía. Pesquisas contemporáneas sobre o Saber Docente. Brasil: editora UNIJUI.

Gimeno Sacristán, J. y Pérez Gómez, Á. (1985). La enseñanza: su teoría y su práctica. Madrid: Akal Universitaria.

Gudmunsdottir, S. (1998). El saber pedagógico sobre los contenidos: una modalidad narrativa del saber. En Mc Ewan, H. y Egan, K. (Comps.), La narrativa en la enseñanza, el aprendizaje y la investigación. Buenos Aires: Aamorrortu.

Jackson, P. W. (2002). Práctica de la enseñanza. Buenos Aires: Amorrortu.

Joyce, B. y Weil, M. (1985). Modelos de enseñanza. Madrid: Anaya.

Litwin, E. (1996). El campo de la didáctica: la búsqueda de una nueva agenda. En Camilloni, A. y otros. Corrientes Didácticas Contemporáneas (pp. 91-115). Buenos Aires: Paidós.

Litwin, E. (1997). Las configuraciones didácticas. Una nueva agenda para la enseñanza superior. Buenos Aires: Paidós.

Mastroccola, M. (1999). El campo intelectual de la Didáctica en la Argentina en los años 60-75. Proposicoes, Vol. 10 (2), 132-148

Montero, L. (2002). La construcción del conocimiento profesional docente. Rosario: Homo Sapiens.

Mc Ewan, H. y Egan, K. (1998). La narrativa en la enseñanza, el aprendizaje y la investigación. Buenos Aires: Amorrortu. 
Pérez Gómez, A. (1987). El pensamiento del profesor: vínculo entre la teoría y la práctica. Revista de Educación, (284), 199-221

Picco, S. (2014). La didáctica crítica y la transformación de las prácticas de enseñanza: Reflexiones en torno a la normatividad. Ponencia presentada en VIII Jornadas de Sociología de la UNLP, Ensenada, Argentina. Recuperado en Memoria Académica: http://www.memoria.fahce.unlp.edu.ar/trab eventos/ev.4515/ev.4515.pdf

Salinas, B. (1995). Límites del discurso didáctico actual. En AA.VV. Volver a Pensar la educación. Prácticas y discursos educativos. (Congreso Internacional de Didáctica), Vol II, (pp. 45-60). Madrid: Fundación Paideia, Morata.

Porta, M. y Cometta, A. (2017). Acerca de los saberes docentes: enfoques y aportes teóricos. Revista Entrevistas, Instituto de Formación Docente “Nuestra Señora del Carmen”, Villa Mercedes. En prensa.

Rockwell, E. y Mercado (1988). La práctica docente y la formación de maestros. Investigación en la Escuela, (4) 65-78

Schön, D. (1992). La formación de profesionales reflexivos. Barcelona: Paidós.

Schön, D. (1998). El profesional reflexivo. Cómo piensan los profesionales cuando actúan. Buenos Aires: Paidós.

Shulman, L. (1989). Paradigmas y programas de investigación en el estudio de la enseñanza: una perspectiva contemporánea. En Wittrock, M. La investigación de la enseñanza I. Enfoques, teorías y métodos (pp. 150-176) Barcelona: Paidós.

Schwab, J. (1974). Un enfoque práctico para la planificación del currículum. Buenos Aires: El Ateneo.

Tardif, M. (2004). Los saberes del docente y su desarrollo profesional. Madrid: Narcea.

Tardif, M. (2014). Saberes docentes e formação profissional. Petrópolis: Vozes.

Terhart, E. (1987). Formas de saber pedagógico y acción educativa. ¿Qué es lo que forma en la formación del profesorado? Revista de Educación (254)

Zeichner, K. (2010). Nuevas epistemologías en formación del profesorado. Repensando las conexiones entre las asignaturas del campus y las experiencias de prácticas en la formación del profesorado en la universidad. Revista Interuniversitaria de Formación del Profesorado, vol. 24 (2), 123-149 